\title{
Lean manufacturing: ações de melhorias em empresa metalmecânica
}

\section{Lean manufacturing: improvement actions in a metalmechanical company}

\author{
Guilherme Saba e Silva Engenheiro de Produção, Universidade Estadual de Maringá \\ (UEM) - guilherme.saba.silva@gmail.com \\ Daiane Maria De Genaro Chiroli Dra. Engenharia de Produção, Universidade Tecnológica Federal \\ do Paraná (UTFPR), Brasil - daianechiroli@utfpr.edu.br
}

\begin{abstract}
RESUMO
O cenário industrial do Brasil estimula a concorrência entre as empresas, portanto visando a sobrevivência no mercado e seu potencial crescimento, atualmente as organizações tendem a buscar novas ferramentas e soluções mais alternativas. O Sistema de Produção Enxuta (SPE) tem recebido grande atenção no cenário mundial, devido aos seus resultados expressivos em corporações no que diz respeito à redução de desperdícios e redução dos custos. Dentro deste contexto, o presente trabalho tem por objetivo propor a aplicação de ferramentas do Sistema de Produção Enxuta (SPE), através da análise do processo produtivo de uma indústria metalmecânica situada no estado do Paraná/PR, Brasil, especializada na produção de implementos agrícolas da linha de pulverizadores. Baseado na pesquisa bibliográfica das técnicas do SPE, apresenta-se um estudo de caso com abordagem qualitativa, desenvolvida uma proposta de aplicação das ferramentas de SPE na referida empresa. A proposta do estudo foi a implantação do Programa 5 Sensos, adequação de Layout e Troca Rápida de Ferramentas como premissas para implantação posterior de demais ferramentas do SPE. Como resultados positivos para a empresa, obteve-se melhor organização do setor, redução do lead time produtivo em $25 \%$ e redução no tempo de setup, melhoria nos tempos de produção, melhor organização, e por fim, padronização das ordens de produção.
\end{abstract}

Palavras-chave: Sistema de Produção Enxuta. 5 S. Melhoria Contínua. Setor Metalomecânico.

\begin{abstract}
The current industrial scenario in Brazil stimulates competition among companies therefore, aiming at survival in the market and their potential growth, organizations are obliged to seek alternative tools and solutions. The Lean Production System (SPE) has received great attention worldwide due to the results obtained in large corporations with regard to waste reduction and cost reduction. In this context, the present work has the purpose of proposing the application of Tools of the Lean Production System (SPE), through the analysis of the production process of a metal-mechanic industry located in the state of Paraná - PR, Brazil, and specialized in the production of a line of sprayers for agriculture. Based on the bibliographic research of the techniques and tools that structure the SPE, a case study is presented. The proposal of the tools to be applied was developed, according to the conditions found in the studied company. It proposed the implementation of the $5 \mathrm{~S} \mathrm{Program} ;$ the layout adaptation and the Rapid Change of Tools as premises for the subsequent implementation of other SPE tools. Some actions were initiated, bringing significant results to the company, as better organization of the sector, reduction of the productive lead time by $25 \%$ and reduction in setup time, improvement in production time, better organization, making it possible to standardize production orders.
\end{abstract}

Keywords: Lean Production System. 5 S. Continuous improvement. Metal-mechanic sector. 


\section{INTRODUÇÃO}

Empresas que atuam no setor metal mecânico enfrentam constantes avanços tecnológicos e necessidades de atualizações periódicas em sua produção para manterem sua competitividade e eficiência, deste modo, se faz necessário identificar os gargalos e suas possíveis soluções (PICCIRILLO; DE GENARO CHIROLI; MELLO, 2016). As atualizações envolvem compras de maquinário mais recente, novas tecnologias, melhorias em seus processos, produtos ou serviços e evolução de seus recursos humanos, assim como sua capacitação. Conforme descrevem Soosay et al. (2016), para empresas sobreviverem, suas habilidades devem se adequar às constantes mudanças do ambiente. Os benefícios primários advindos desses aprimoramentos são: redução do tempo de setup e do lead time, maior controle sobre a qualidade dos produtos e processos, corpo de funcionário capacitado, acarretando assim redução do custo de produção (fixos e variáveis) e possibilitando o crescimento da empresa, bem como de seus funcionários. O sistema Leané utilizado de forma abrangente nas práticas de muitas empresas, demonstrando grandes avanços na eficiência produtiva (LIU et al., 2013).

Porém para a implementação dessas melhorias, a planta produtiva deve estar organizada e preparada, neste sentido, as organizações se esforçam para implementar novas filosofias de fabricação que permitam suprir as mudanças exigidas por seus clientes, ofertando produtos com alta qualidade, fabricados com menor tempo e custo (JASTI; KODALI, 2016). Com o intuito de atender a essas premissas e se preparar para receber melhorias na logística interna de produção, a empresa estudada buscou ferramentas e técnicas que trouxessem um nível de organização (cultural e organizacional) que permitisse uma coleta de dados confiável, e assim auxiliasse na implantação de quaisquer mudanças na estratégia produtiva dessa organização.

Situada no norte do estado do Paraná, a empresa atua no segmento metalmecânico e enfrentava problemas com perdas de ferramentas e peças, altos tempos de setup e lead time e constantes discrepâncias entre os dados reais e os fornecidos pelo sistema. Esta empresa assume uma posição de destaque perante seus concorrentes, principalmente na região Sul do país, onde conta com grandes companhias transportadoras para efetuarem o transporte de sua mercadoria até seus clientes, que são agropecuaristas ou revendedores de máquinas agrícolas. A principal exigência dos consumidores refere-se à durabilidade das peças. A empresa produz uma linha de peças de reposição para pulverizadores e plantadeiras de diversas marcas, tais como, como Baldan, Jacto, John Deere, Montana, Semeato e Valtra.

Conforme destacam Prajogo, Oke e Olhager (2016), necessita-se de uma gestão adequada nos produtos, serviços e informações em todos os elos pertencentes à cadeia para se obter uma confiável e uniforme produção, assim, desenvolveu-se uma proposta baseada nas filosofias dos Cinco Sensos (5S), adequação do layoute método da Troca Rápida de Ferramentas (TRF) como sendo precursores à implantação de uma estratégia Lean de produção. Rago et al. (2003), descrevem que os dez passos cruciais para a implantação do sistema Lean são: (1) Liderança e satisfação do cliente; (2) Envolvimento das pessoas; (3) Aliança com fornecedores; (4) Qualidade na fonte; (5) Gestão à vista; (6) Manutenção produtiva; (7) Troca rápida de ferramentas; (8) Puxar a produção; (9) Redução do tempo de ciclo; e (10) Controle e redução de custos. Para De Genaro Chiroli et al. (2016), a imagem da qualidade dos produtos ou serviços é um fator-chave na decisão de compra por parte dos clientes, sendo assim, se faz necessário estabelecer medidas a serem tomadas, com a finalidade de preparar a organização, para receber a aplicação do Sistema Lean, conforme ilustra a Figura 1. 
Figura 1- Ferramentas da Filosofia Enxuta
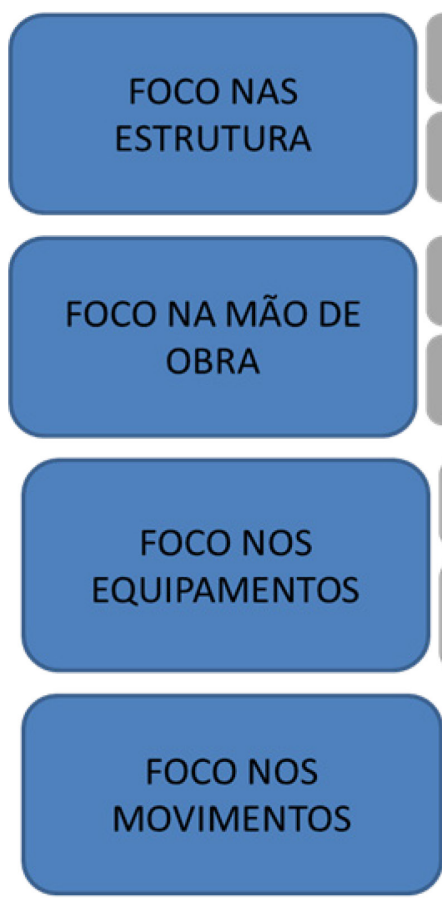
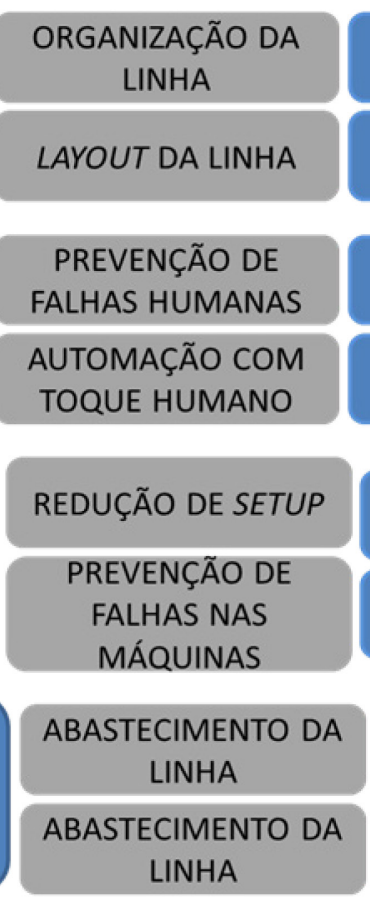

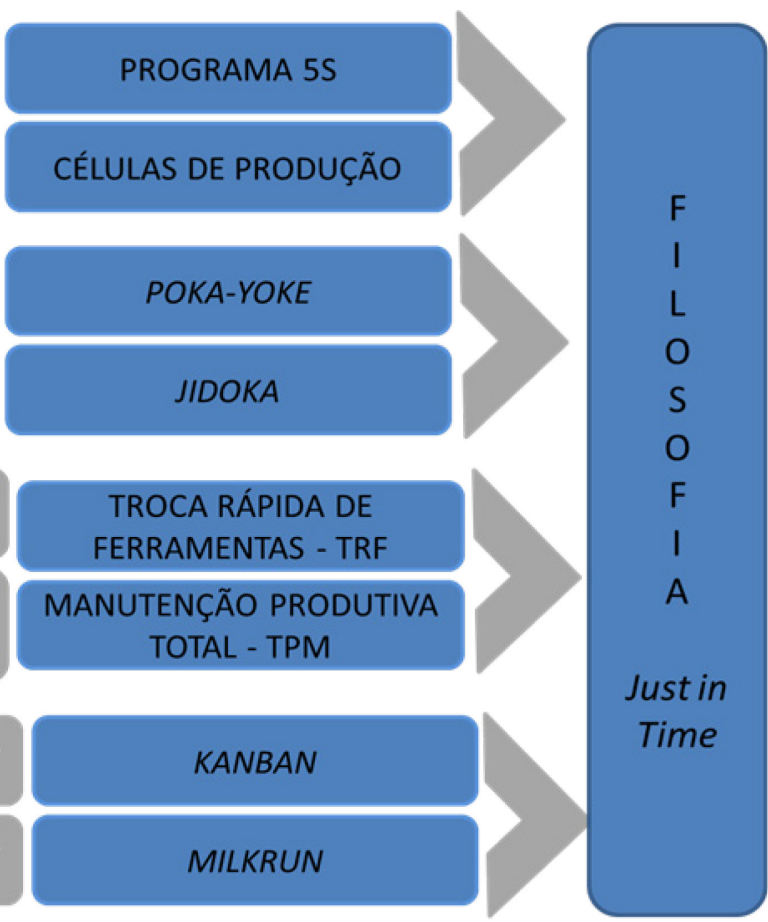

Fonte: Rodrigues (2014, p. 68).

Para o desenvolvimento do presente trabalho, utilizou-se as ferramentas: Programa dos Cinco Sensos, Adequação de layout da linha e redução de setup, por meio da Troca Rápida de Ferramentas. A escolha destas ferramentas se deu por serem as precursoras das restantes no Sistema de Produção Enxuta.

Dentro deste contexto, o presente estudo buscou responder ao seguinte questionamento: Como conduzir melhorias no setor de soldas de uma empresa do setor metalmecanico?

Assim, o objetivo deste trabalho é o propor a de aplicação de ferramentas do Sistema de Produção Enxuta (SPE), através da análise do processo produtivo de uma indústria metalmecânica situada no estado do Paraná - PR, Brasil, especializada na produção de implementos agrícolas da linha de pulverizadores.

Como objetivos específicos teve-se: estudar as condições atuais: Avaliação do estágio de organização apresentado no processo produtivo; (2) identificar os parâmetros estratégicos que permitirão a aplicação do sistema de produção enxuta; e (3) propor um plano de ação para implementar o SPE.

\section{REFERENCIAL TEÓRICO}

Para garantir a excelência na qualidade de seus produtos ou serviços, as empresas têm que buscar melhorar seu ambiente competitivo (SAKUMOTO; CHIROLI; DZULINSKI, 2019; CONCEIÇÃO et al., 2019). Para Antony $(2005,2006)$ o SPE remove barreiras e agrega valor, pois permite melhor fluidez dos processos, por torná-los mais rápidos, elimina o desperdício a partir de processos críticos, reduz o número produtos/operações defeituosos e o prazo para a entrega do produto/serviço. Para alcançar estes resultados, ferramentas como o Programa cinco censos (5S), Adequação de layout da linha e Troca Rápida de Ferramentas são fundamentais, estas serão descritas a seguir.

O Programa dos 5S foi criado no Japão pós-guerra (década de 50), devastado, cada S expressa um significado originário do idioma japonês. São interpretados como sensos, com a finalidade de exprimir ideia de mudança comportamental (SILVA, 1994). Os cinco sensos exprimem: $1 \circ \mathrm{S}$ : Seiri, senso de utilização; $2^{\circ} \mathrm{S}$ : Seiton, senso de ordenação; $3^{\circ} \mathrm{S}$ : Seiso, senso de limpeza; $4^{\circ} \mathrm{S}$ : Seiketsu, senso de saúde; $5^{\circ}$ S: Shitsuke, senso de autodisciplina. O programa em si é relativamente simples, onde os três primeiros passos proporcionam 
resultados grandiosos, porém a manutenção e melhoria do programa a longo prazo são extremamente dispendiosos.

De acordo com Corrêa e Gianesi (2007), em meados da década de 70, com base no Sistema Lean, os japoneses inovam com o conceito de linhas de produção, garantindo que o trabalho organizado em linhas, elimina desperdícios de espera, superprodução, estoque, defeitos de qualidade, movimentos, transportes, processos desnecessários, além de proporcionar um ambiente de trabalho polivalente, seguro, saudável e ergonômico. As trocas rápidas de ferramentas são um requisito indispensável para o Sistema Lean, pois segundo Ohno (1997) "A troca de ferramenta era considerada um elemento que reduzia eficiência e aumentava custos.". As oito principais técnicas de reduzir o tempo de setup são (SHINGO, 1996): (1) Separação das Operações de set up Internas e Externas; (2) Converter setup interno em externo;(3) Padronizar a função e não a forma;(4) Utilizar Grampos Funcionais ou Eliminá-los; (5) Utilizar Dispositivos intermediários; (6) Adotar Operações Paralelas; (7) Eliminar Ajustes; (8) Mecanização.

\section{METODOLOGIA}

Melhorias a serem implantadas em processos requerem um estudo detalhado da situação em que se encontra, para efetuar estudos de ferramentas viáveis a serem aplicadas. Para este estudo, primeiramente foi realizada coleta de dados qualitativos da empresa, alinhado com uma observação da célula produtiva a ser estudada. Com os dados em mãos serão delimitadas a necessidades do setor a ser estudado. Para Martins (2012), na abordagem qualitativa, busca-se obter informações sobre a perspectiva dos indivíduos, interpretar o ambiente em que a problemática acontece, de modo a coletar evidencias.

Posteriormente, foi realizada então uma pesquisa exploratória a fim de alinhar a situação encontrada na empresa (problemas) as metas e objetivos das necessidades encontradas de acordo com as características presentes da literatura. A pesquisa exploratória é capaz de proporcionar familiaridade com o problema, com a intenção de explicitá-lo ou a construir hipóteses (GIL, 1991).

Para o desenvolvimento do trabalho, o primeiro passo foi a pesquisa bibliográfica a respeito de ferramentas do Sistema de Produção Enxuta, em especial Filosofia dos 5S, Layout enxuto e Troca Rápida de Ferramentas (TRF). Com base nos dados bibliográficos, alinhou-se as ferramentas estudadas ao cenário atual encontrado na concedente. Concluída essa etapa foi definida uma estratégia a ser tomada para a criação do trabalho, conforme ilustrado na Figura 2.

Figura 2 - Passos para o desenvolvimento do estudo

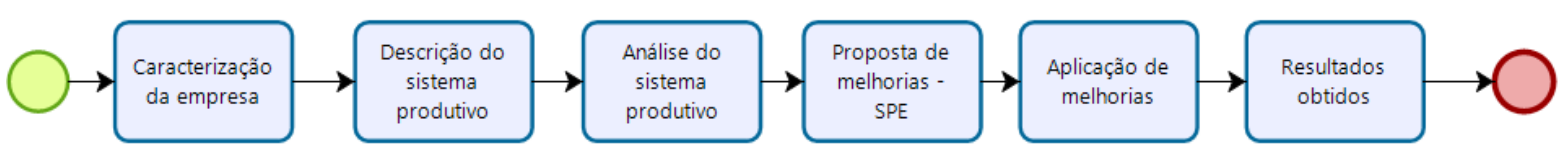

Fonte: os autores (2019).

\subsection{Caracterização da empresa}

A empresa estudada será denominada de empresa $X$ neste trabalho. Esta, se encontra localizada na região norte do estado do Paraná - Brasil, atua no mercado de peças de reposição nas linhas de plantadeira e pulverização. Visa atender as necessidades dos seus clientes, e preza por uma produção de peças de extrema confiabilidade e qualidade, proporcionando aos seus compradores agilidade e rapidez nas entregas de seus produtos. A missão da empresa é: "Atuar no ramo de manutenção de equipamentos agrícolas, fornecendo produtos com qualidade e confiabilidade". A visão da empresa é: "Ser referência na região Sul do país na fabricação de peças para implementos agrícolas". Os valores pregados na empresa são transparência, responsabilidade e confiança. 
Visando a durabilidade de seus produtos, a empresa $X$ assume uma posição de destaque perante seus concorrentes, principalmente na região Sul do país, onde conta com grandes companhias transportadoras para efetuarem o transporte de sua mercadoria até seus clientes, que são agropecuaristas ou revendedores de máquinas agrícolas. A principal exigência dos consumidores refere-se à durabilidade das peças.

\subsection{Caracterização dos processos logísticos}

A empresa $X$ é constituída por dois grandes pavilhões. No primeiro encontram-se todo o setor administrativo (recepção, compra, gerência, financeiro), o setor produtivo inicial (estoques, máquinas de cortes, solda, tornos etc.) e o setor de expedição. Já no segundo pavilhão estão localizadas as atividades de acabamento, como limpeza e pintura das peças. Quanto à utilização de tecnologia, possui uma máquina de corte a plasma, dois tornos do tipo CNC, um torno convencional, uma cabine de pintura Epoxi e três bancadas de solda do tipo TIG. As demais máquinas e equipamentos que a empresa possui não apresentam um alto nível de sofisticação.

A matéria-prima (aço, ferro ou alumínio) passa por processos internos da fábrica, para transformá-los em componentes para as peças maiores, ou para serem vendidos diretamente. Após produzidos os subprodutos iniciais, estes são armazenados em um almoxarifado, para uso posterior na montagem de outras peças, através do processo de solda. Assim, outros componentes como tubos, suportes e buchas são fabricados. Tomando como base um gabarito, formam-se finalmente as peças maiores, como um quebracabeça. Depois esses produtos passam por uma limpeza e, posteriormente, seguem para o setor de pintura, onde são pintados de acordo com suas marcas. Pintados e secos, eles seguem para o estoque, onde aguardam para serem comercializados. O layout físico da empresa é representado por meio da Figura 3.

Para compreender a Figura 3, tem-se na empresa (1) setor de pintura; (2) prensa; (3) estantes de matéria-prima; (4) estante de gabaritos; (5) tanque de limpeza; (6) serra automática; (7) rebite; (8) furadeira; (9) torno; (10) torno CNC; (11) freza; (12) corte à laser; (13) solda; (14) estoque de componentes; (15) PCP; (16) estoque de produtos acabados; (17) expedição; (18) setor administrativo. O fluxograma da empresa é apresentado na Figura 4, onde estão resumidos a ordem e os processos envolvidos nas fabricações dos diversos produtos da empresa.

Figura 3 - Layout da empresa X

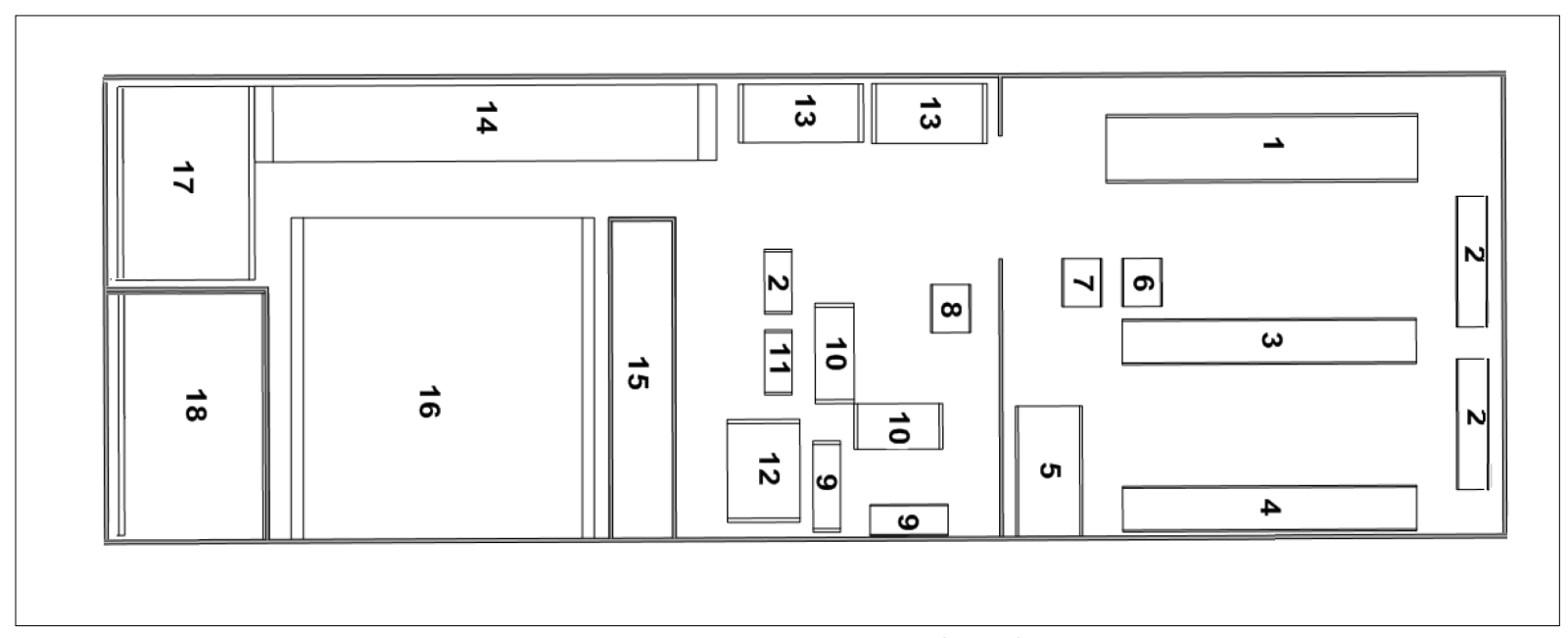

Fonte: os autores (2019).

O transporte de matérias-primas para seus processamentos, são feitos por apenas uma empilhadeira. Depois de serem processados em peças menores eles são transportados dentro de caixas, com auxílio de uma paleteira e cinco carrinhos de transporte industrial, efetuados por três auxiliares de produção e um movimentador contratados. Essa matéria-prima é transformada em componentes, para posterior montagem 
dos produtos acabados. Esses componentes são armazenados no estoque intermediário em estantes e caixas personalizadas de acordo com os tamanhos das peças. Com a liberação da produção dos produtos, os componentes são liberados pela encarregada de almoxarifado mediante apresentação das ordens de produção. Os componentes são transportados pelo movimentador com a paleteira e com os carrinhos até o setor de solda (montagem). Depois de soldados, os produtos semiacabados são transportados pelo movimentador com a empilhadeira até o setor de lavagem e pintura. Depois de pintados os produtos acabados são transportados novamente pela empilhadeira e pelo movimentador até o estoque de produtos acabados. De acordo com as vendas, os produtos são então encaminhados para a expedição pelo encarregado de expedição e seu auxiliar, sem auxílio de ferramentas movimentadoras. Os produtos são então embalados com auxílio de cavaletes, e encaminhados para dentro dos caminhões na doca de expedição.

Figura 4 - Fluxograma dos processos empresa $X$

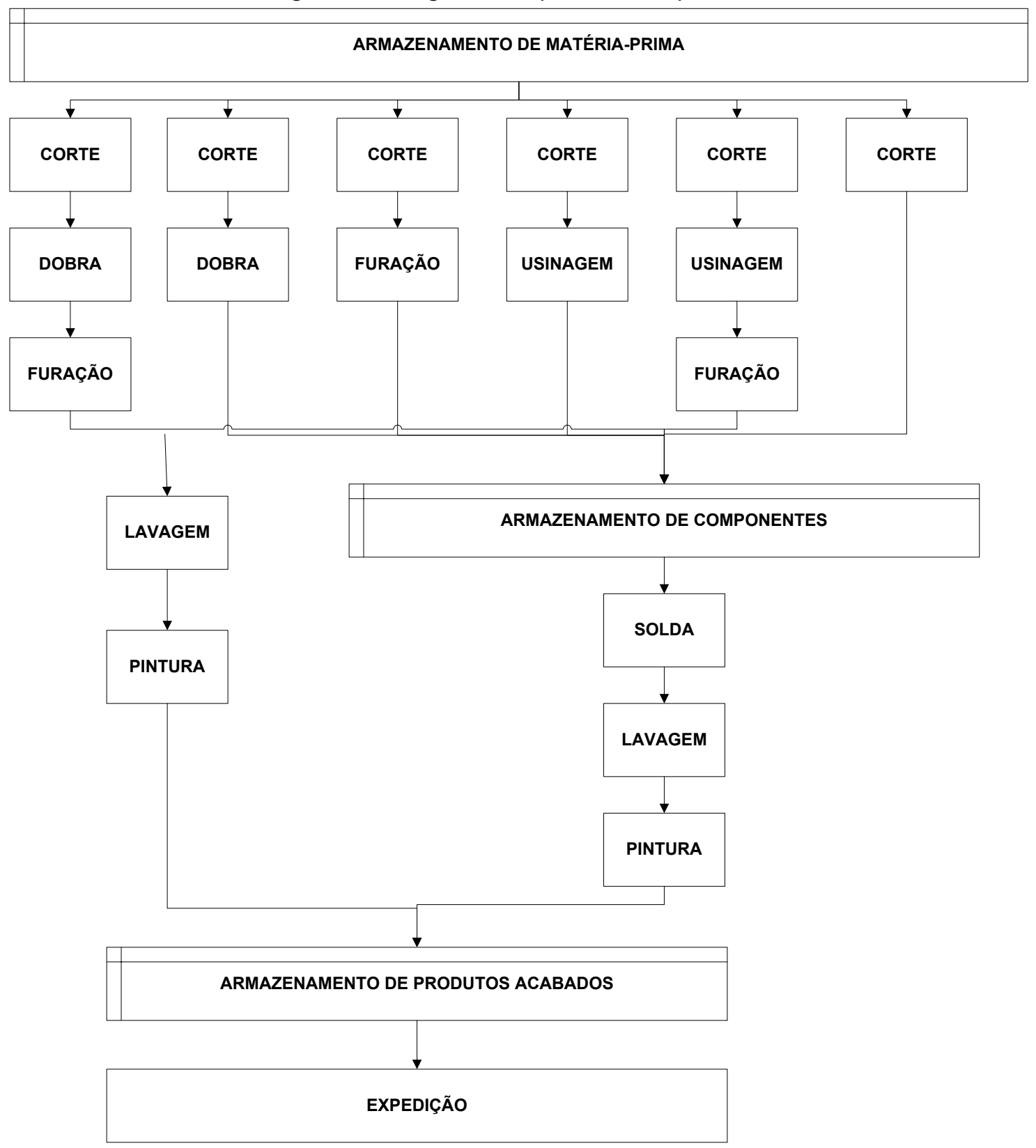

Fonte: os autores (2019).

Após compreendido toda relação das atividades logísticas da organização, foi possível observar e identificar problemáticas, estas descritas no tópico seguinte. 


\section{DESENVOLVIMENTO DO CASO PRÁTICO}

Nesta seção serão apresentados os passos metodológicos, para cumprir aos objetivos propostos.

\subsection{Análise do sistema produtivo}

Após levantamento das informações do processo logístico da empresa, pôde-se elencar/identificar falhas em toda a fábrica, em especial no setor de solda, as quais impactam nos resultados financeiros e de qualidade da empresa.

Erros na acuracidade de estoques: existem três estoques na empresa, de matéria-prima, de subprodutos e de produtos acabados. O controle de matéria-prima é feito pelo encarregado de produção e pelo setor de compras, ocorrendo frequentemente divergências nas quantidades reais de estoques e as apresentadas pelo sistema. O estoque de componentes é gerido pelo encarregado de almoxarifado, e divergências nas quantidades são encontradas em algumas situações. Já o estoque de produtos acabados é controlado pelo encarregado de expedição e pelo setor de vendas pelas entradas de NFs, e ocorrem divergências com certa frequência também.

Grandes quantidades de produtos e componentes em estoque: devido à grande variedade de produtos vendidos na empresa, venda a pronta entrega e baixa flexibilidade da planta produtiva, a empresa armazena grande quantidade de itens (matéria-prima, componentes e produtos acabados).

Faltas de produtos em estoque: alguns pedidos recebidos no setor de vendas não podem ser concluídos pelo fato de não haver certos produtos em estoque e oferecerem os produtos a pronta entrega aos clientes.

Índices de avarias: no transporte do estoque até a expedição podem ocorrer choques dos produtos, causando falhas nas pinturas, e soldas dos mesmos, tendo que ser separados dos produtos conformes e encaminhados para retrabalhos.

Perda de ferramentas: devido à falta de organização da planta produtiva, diversas ferramentas são perdidas ou leva-se muito tempo até os operadores as localizarem, elevando consequentemente os lead times, tempos de setup e causando avarias nessas reduzindo sua vida útil.

Excesso de movimentação: foi observada através de um “Diagrama Spaghetti” uma movimentação excessiva realizada pelo operador do setor de solda.

Retrabalhos: peças depois de soldadas, apresentavam problemas de qualidade, como falhas na solda, falta de componentes.

Absenteísmo e turnover: o trabalho realizado pelo soldador apresenta diversos problemas ergonômicos, além disso o excesso de movimentação e problemas com os componentes geram uma alta taxa de absenteísmo e rotatividade de funcionários.

Refugo: Diversos produtos eram refugados pelos compradores por não atenderem às especificações desejadas devido a erros no processo de soldagem.

Pouca flexibilidade: Devido ao tamanho exagerado das peças produzidas, os tempos de setup são muito elevados, pois exigem o auxílio de movimentação de uma empilhadeira.

A partir da identificação desses problemas, foi identificado que o gargalo da empresa está no setor de solda, uma vez quase todas as peças são processadas neste. Deste modo, a escolha deste trabalho ser realizado neste setor se justifica, pois setor trará grandes benefícios para a organização. É estimado que existam aproximadamente 70 processos de solda em nível mundial; no setor estudado é utilizado a solda MIG (Metal Inert Gas), que se dá por meio de um arco elétrico entre a peça a ser soldada e o metal consumível, arame ou eletrodo não revestido, o que proporciona o aquecimento e fusão dos materiais, realizando sua união. 


\subsection{Proposta de melhorias}

A escolha das melhorias foi efetuada considerando as condições apresentadas pela empresa, assim como a simplicidade das ferramentas, reduzindo a necessidade de recursos como pessoas, investimentos e tempo, com a finalidade de se obter maiores resultados com a menor quantidade de recursos. Assim foram selecionadas 3 ferramentas presentes no Sistema Lean: Filosofia dos 5 Sensos; Adequação de layout eTroca Rápida de Ferramentas.

\subsubsection{Filosofia dos Cinco Sensos}

A implantação da Filosofia dos 5 Sensos não se trata apenas de mudanças e melhorias realizadas na planta produtiva em nível estrutural, mas sim mudanças culturais, que devem atingir a organização inteira.

A proposta leva essa ferramenta para todos os setores presentes na organização, pois de nada adianta ser implantada em um setor separadamente. $\mathrm{O}$ tempo proposto suficiente para se atuar em cada local, por etapa presente no programa ( 5 etapas), é de uma semana. Como prevê-se participação de todos colaboradores, pode-se realizar o trabalho simultaneamente em até 4 setores segundo a programação dos elaboradores do projeto. $\mathrm{Na}$ etapa de planejamento foram identificadas as possíveis melhorias que poderiam ser realizadas em cada setor, como são descritos alguns exemplos a seguir das ações propostas relacionadas ao setor de solda.

Os tempos de separação de componentes, para serem soldados no setor estudado, são muito altos, por não haver nenhum critério de organização no estoque. Os gabaritos de solda da empresa eram dispostos sem nenhum critério de ordenação e organização, demandando o auxílio do encarregado de produção para identificar e instalar essas ferramentas no setor de solda. Existem pinos fixadores que auxiliam na colocação dos componentes nesses gabaritos. Esses pinos apresentam variadas espessuras de acordo com a peça a ser produzida. Se houvesse uma separação destes, de acordo com a bitola (diâmetro do pino), o soldador seria poupado de efetuar tentativas no momento de fixar o componente ao gabarito até encontrar o tamanho certo. Outra opção seria deixar os pinos presos aos gabaritos por correntes nas posições desejadas, porém geraria um aumento significativo do peso desses dispositivos, e seria necessário alto investimento em materiais.

O setor estudado apresentou quantidade de sujidades, como poeiras, peças jogadas pelo chão, materiais de consumo descartados. Com uma metodologia de limpeza diária, de aproximadamente 5 minutos por dia, seria capaz de melhorar as condições ergonômicas do trabalho no setor, reduzindo o índice de absenteísmo, acidentes de trabalho e turnoverno local. Além dessas melhorias relacionadas à mão-de-obra, a instalação de exaustores no setor reduziria também a presença de fumaça e fuligens no local. $O$ acompanhamento do programa depois da fase de implantação deve ser realizado periodicamente com a intenção de se manter o que foi conquistado durante a implantação, assim deve-se avaliar o ambiente.

A partir desses exemplos, os identificados no setor devem ser calculados e depois se divide esse valor encontrado de itens não conformes, pelo total de itens listados (conformes e não conformes), tendo assim uma graduação de 0 a 1 , que se multiplicada por 100 se transforma em porcentagem.

Com as graduações obtidas é possível obter indicadores capazes de avaliar o grau de amadurecimento e aceitação de cada setor, em termos numéricos, facilitando tomadas de decisão para a manutenção do programa futuramente. Deve ser definida também uma equipe multidisciplinar composta preferencialmente por pelo menos três integrantes de diferentes setores, incluindo a alta administração, sendo necessário um gerente do projeto, um secretário geral e um membro responsável pela execução das melhorias.

No primeiro $S$ do programa notou-se a presença de todos os gabaritos pequenos de solda no próprio setor, sendo que a frequência de utilização destes variava de 1 a 3 vezes por ano, surgiu assim a necessidade de retirá-los do local. Além dos gabaritos havia diversas ferramentas como alicates (corte e bico), sargentos, talhas, marretas entre outras em excesso no local. Verificou-se inclusive, material de dejetos do processo como carretéis de arame de solda e componentes refugados de diversos produtos no chão do setor. Foi então eliminado o excesso de uso das ferramentas, todos os gabaritos de solda ali presentes e dejetos encontrados. 
No segundo $S$ foi realizada a identificação de todos os gabaritos de solda ali utilizados, sendo transferidos para outro setor (armazém) e alocados em estantes fabricadas especialmente para esses e estaleiros capazes de comportar os gabaritos maiores. Nessas estantes eles foram divididos de acordo com as marcas dos produtos que neles eram produzidos. Foi padronizada a localização dos mesmos e criou-se códigos de identificação para cada um deles. O mesmo critério de organização foi adotado na organização dos componentes em seu estoque. Os códigos criados foram inseridos nos dados das ordens de produção com a finalidade de facilitar o trabalho do movimentador. Foi instalado no setor um painel de ferramentas para melhorar a organização dessas no local, padronizando suas posições.

A armazenagem dos gabaritos de solda no setor externo à solda facilitou consideravelmente a visualização dessas ferramentas, reduzindo o tempo de procura das mesmas, além de liberar grande quantidade de espaço no setor de solda, melhorando as condições ergonômicas de trabalho do operador. Tais mudanças foram importantes para a mudança de layout pois o espaço do setor em estudo foi ampliado devido à retirada dessas peças.

\subsubsection{Adequação do Layout}

Na proposta de adequação de layout deve-se avaliar: dimensão das áreas do equipamento, do processo, do operador, do acesso ao processo tanto do operador como de meios de transporte e movimentação, ferramentas, resíduos que devem ser levados em consideração. O Layout estudado antes das melhorias apresenta diversas limitações de movimentação ao soldador (Figura 5), assim como falta de dispositivos que permitam melhor acondicionamento dos componentes a serem soldados (em espera), dificultando o trabalho do operador.

Figura 5 - Layout antes das melhorias

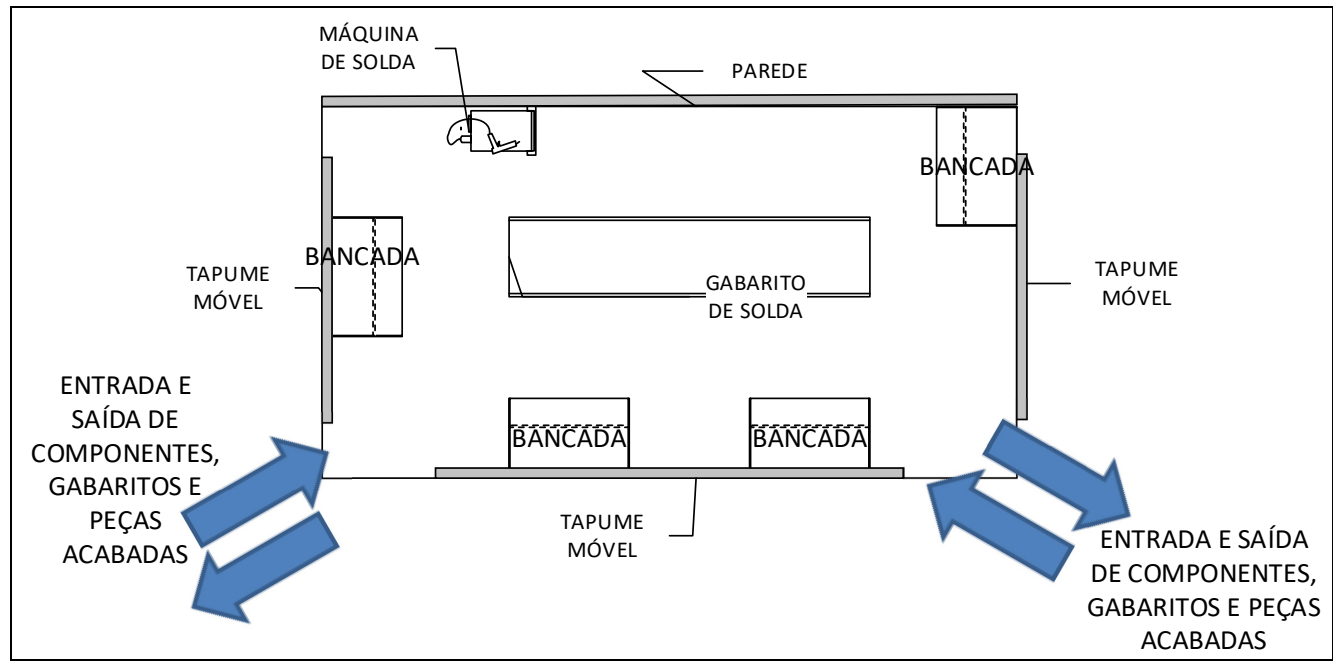

Fonte: os autores (2019)

Existem alguns fatores importantes a serem avaliados na proposta de adequação de layout como dimensão das áreas do equipamento, do processo, do operador, do acesso ao processo tanto do operador como de meios de transporte e movimentação, ferramentas, resíduos e a logística apresentada pelos processos produtivos que devem ser levados em consideração. Além do layout em si, devem ser utilizadas ferramentas como fluxogramas, com a finalidade de demonstrar as relações entre os processos e auxiliar na tomada de decisão.

Foi realizado um Diagrama Spaghetti para avaliar as necessidades de dispositivos e liberações de espaço do local, o qual permitiu identificar a movimentação interna no setor, entre a peça e as bancadas, diversas movimentações para fora do setor. Isso se dá pelo fato de os tubos maiores para a produção não poderem ser acondicionados dentro do setor, obrigando o soldador a sair de seu local de trabalho para buscar 
componentes. A excessiva movimentação interna ao setor ocorre, pois os componentes são dispostos sem critério pelas bancadas presentes no setor, fazendo com que o operador tenha que procurar os componentes pelas caixas no local e se desloque as vezes de uma ponta a outra da peça apenas para pegar um componente.

Para melhorar a utilização do espaço disponível no local foi proposto a inserção de bancadas multitarefas móveis, estaleiros para tubos e mobilidade dos limites físicos do centro de trabalho; são medidas que poderiam melhorar consideravelmente a dinâmica de trabalho do operador, assim como estruturalmente. Com a finalidade de se obter melhorias estruturais e da dinâmica da mão de obra, foram instaladas bancadas especiais, posicionadas nas extremidades e no meio do setor, de modo a reduzir a movimentação do soldador na hora de coletar os componentes para posicioná-los nos gabaritos. O movimentador foi treinado para separar os componentes e agrupá-los em caixas de acordo com seu posicionamento no produto, sendo que os subprodutos pertencentes a parte traseira seriam alocados próximos a essa extremidade, as da parte dianteira próximos a essa ponta e as do meio localizadas no meio do setor.

Foi construído um rack para a colocação dos tubos mais compridos que seriam soldados, eliminando a movimentação do operador para fora do setor. Foi instalada também uma ponte rolante sobre o setor para colocar a máquina de solda, a fim de liberar espaço e facilitar o alcance da mangueira de solda nos locais de difícil acesso dos gabaritos. As modificações são demonstradas na Figura 6.

Todas essas melhorias reduziram drasticamente o lead time no setor de aproximadamente 3 horas para 2 horas e 15 minutos.

Figura 6 - Novo layout

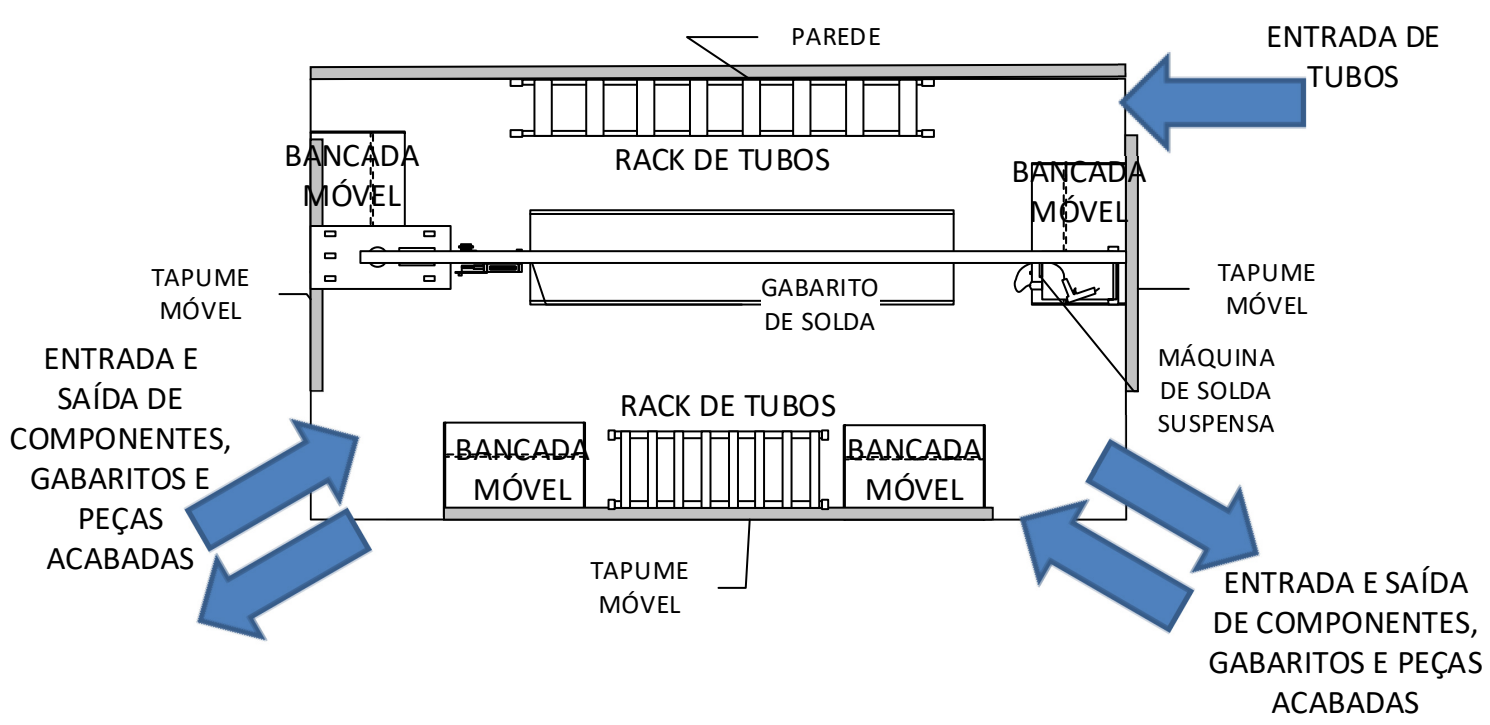

Fonte: os autores (2019).

\subsubsection{Troca Rápida de Ferramentas}

Dispositivos de fixação e remoção rápidas são fatores importantes que auxiliam nas melhorias com a ferramenta da Troca Rápida de Ferramentas. Grampos rápidos, medidas padronizadas desses dispositivos são exemplos de melhorias capazes de trazer benefícios na redução dos tempos de setup em nível de equipamentos através da eliminação de ajustes. Existem dispositivos rotativos, com cavaletes, que permitem a instalação rápida, por meio de grampos e de eliminação de ajustes, que podem facilmente ser construídos e utilizados no setor estudado.

A conversão de atividades de setup interno em setup externo são medidas que, através da criação de métodos e treinamentos para a mão de obra relacionada, podem também reduzir os tempos de setup consideravelmente, pois assim, com a adoção de operações paralelas, não é necessária a parada do operador 
do setor em questão, para realizar o setup dentro do local. O movimentador já pode deixar as ferramentas próximas ao setor, separadas, preparadas e agrupadas apropriadamente, sendo que no momento em que o soldador interromper a atividade de solda para troca de ferramentas, ele não tenha que se locomover para pegá-las, ou perder seu tempo para prepará-las.

Para a troca rápida de ferramentas foram instalados cavaletes de engate rápido, para os gabaritos de solda, assim como adaptações nos gabaritos já existentes (Figura 7), facilitando sua instalação e remoção, além de que as melhorias realizadas com o programa $5 \mathrm{~S}$ de identificação e organização dos gabaritos, foram de extrema importância na transformação dos setups internos em setups externos, sendo que um operador contratado como movimentador, consegue realizar quase todo o trabalho sozinho, de identificação (criação de códigos presentes nas ordens de produção e nos próprios dispositivos), transporte (através de uma empilhadeira) e instalação (necessário o auxílio do soldador, porém tempo extremamente reduzido).

Figura 7 - Cavalete giratório de engate rápido

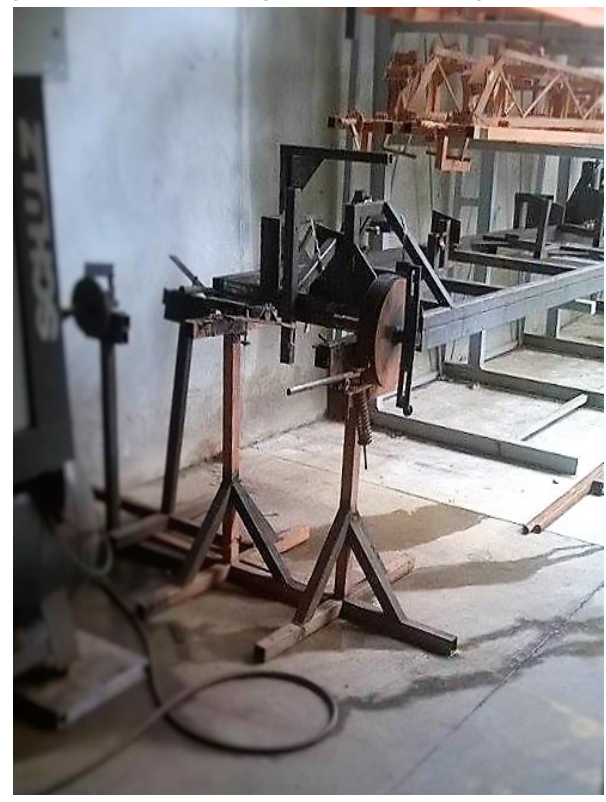

Fonte: os autores (2019).

O cavalete rotativo, com presilhas de engate rápido reduziu consideravelmente o tempo de troca de gabaritos, assim como o lead time por proporcionar condições ergonômicas do soldador poder mover os gabaritos sozinho.

\section{CONCLUSÃO}

Com a implantação parcial das ferramentas citadas, a empresa obteve aproximadamente 15\% de aumento em sua produtividade, segundo dados recebidos do gerente de produção. Isso pode demonstrar os recursos, como tempo e materiais, que eram desperdiçados na produção e puderam ser reduzidos com as ferramentas do Sistema de Produção Enxuta.

A filosofia dos Cinco Sensos proporcionou redução significativa dos tempos de setup, pelo fato de um movimentador ser capaz de realizar as atividades que antes demandavam a supervisão do encarregado e mão de obra adicional de dois operadores. O tempo de procura pelas ferramentas corretas a serem utilizadas (gabaritos de solda) foi praticamente anulado, sendo que o código da ferramenta e sua respectiva localização já vêm presentes nas ordens de produção, cabendo ao movimentador apenas a tarefa de movimentar, e não tomar decisões. Após a adequação do layout do setor de solda pôde-se avaliar com o auxílio do Diagrama Spaghetti a diminuição significativa da movimentação realizada pelo soldador no interior de seu setor. Ele não teve que se ausentar do local em nenhum momento, durante a avaliação, pois todos os componentes 
necessários estavam dentro do setor e ao seu alcance. O tempo analisado da soldagem da peça analisada foi reduzido de 3 horas para aproximadamente 2:15 horas, sendo este, um resultado a nível estrutural, extremamente satisfatório para o estudo.

Além de melhoria nos tempos de produção, o nível de organização atingido pelos colaboradores e pela empresa em geral, deu grande suporte para o setor de PCP, sendo que todas as informações criadas e algumas já existentes foram inseridas nas ordens de produção, listando as etapas e ferramentas necessárias para a mesma. Essas mudanças fizeram com que a dependência dos colaboradores de auxílio do encarregado de produção fosse reduzida, dando a ele mais tempo livre para o desenvolvimento de novos produtos.

Foram enfrentadas diversas limitações na realização deste trabalho, especialmente na aprovação e implantação das melhorias. Os principais limitantes encontrados foram referentes à recursos como tempo, materiais e investimentos; e a resistência dos colaboradores à mudança.

A partir das mudanças realizadas e dos resultados obtidos, a alta direção da empresa foi capaz de traçar planos de melhorias, focadas nas ferramentas propostas pelo trabalho e alinhadas ao planejamento estratégico. As próximas etapas rumo à eliminação dos desperdícios mencionados seriam a implantação de ferramentas como Kanban e Manutenção Produtiva Total.

\section{REFERÊNCIAS}

ANTONY, Jiju. Assessing the status of six sigma in the UK service organizations. In: NATIONAL CONFERENCE ON SIX SIGMA (CSS' 05), 2., 2005, Wroclaw, Poland. Proceedings... Wroclaw: [s.n.], 2005. p. 1-12.

ANTONY, Jiju. Six Sigma for service processes. Business Process Management Journal, v. 12, p. 234-248, 2006. DOI: 10.1108/14637150610657558. Disponível em: https://www.emerald.com/insight/content/doi/10.1108/14637150610657558/full/html. Acesso em: 10 maio 2019.

CORRÊA, H. L.; GIANESI, I. G. N. Just in Time, MRP II e OPT: um enfoque estratégico. 2. ed. São Paulo: Atlas, 2007.

CONCEIÇÃO, Rodrigo Subirá et al. Lean six sigma: implementation of improvements to the industrial cost management. Independent Journal of Management \& Production, v. 10, p. 2023-2045, 2019.

DOI: http://dx.doi.org/10.14807/ijmp.v10i6.996. Disponível em:

http://www.ijmp.jor.br/index.php/ijmp/article/view/996/1228. Acesso em 03 dez. 2019.

DE GENARO CHIROLI et al. A study on the quality costs in a metalworking company. Espacios, Caracas, v. 37 , n. 04, p. 19-19, 2016.

GIL, A. C. Como elaborar projetos de pesquisa. São Paulo: Atlas, 1991.

JASTI, N. V. K.; KODALI, R. Development of a framework for lean production system: An integrative approach. Journal of Engineering Manufacture, v. 230, p. 136 - 156, 2016 . DOl.org/10.1177/0954405415596141. Disponível em: https://journals.sagepub.com/doi/abs/10.1177/0954405415596141 ?journalCode=pibb. Acesso em: 9 maio 2019.

LIU, S. et al. A decision-focused knowledge management framework to support collaborative decision making for lean supply chain management. International Journal of Production Research, v.51, p. 21232137, 2013. DOI. org/10.1080/00207543.2012.709646. Disponível em: https://www.tandfonline.com/doi/full/10.1080/00207543.2012.709646. Acesso em: 3 abr. 2019.

MARTINS, Roberto Antônio. Abordagem quantitativa e qualitativa. In: MIGUEL, Paulo Augusto Cauchick (org.). Metodologia de pesquisa para engenharia de produção e gestão de operações. Rio de Janeiro: Elsevier: ABEPRO, 2012. p. 47-63.

OHNO, T. O Sistema Toyota de Produção: além da produção em Larga Escala. Porto Alegre: Artes Médicas, 1997. 
PICCIRILLO, Isabela Neto; DE GENARO CHIROLI, Daiane Maria; MELLO, Luciana Torres Correia de. Routing with sweeping method: a proposal to improve the formatting loads, reduce costs and meet customer. Espacios, Caracas, v. 37, n. 04, p.18-18, 2016.

PRAJOGO, D.; OKE, A.; OLHAGER, J. Supply chain processes: Linking supply logistics integration, supply performance, lean processes and competitive performance. International Journal of Operations \& Production Management, v. 36, p. 202-238, 2016. DOI. org/10.1108/IJOPM-03-2014-0129. Disponível em: https://www.emerald.com/insight/content/doi/10.1108/IJOPM-03-2014-0129/full/html. Acesso em mai. 2019.

RAGO, S. F. T. et al. Atualidades na gestão da manufatura. São Paulo: IMAM, 2003.

RODRIGUES, M. V. Entendendo, aprendendo e desenvolvendo sistemas de produção Lean Manufacturing. Rio de Janeiro: Elsevier, 2014.

SAKUMOTO, S. M.; DE GENARO CHIROLI, D. M.; DZULINSKI, A. C. Using Lean Six Sigma to Increase Efficiency of a Grain Receipt Process of a Brazilian Agroindustry Cooperative. American Journal of Engineering and Applied Sciences, v. 12, p. 214.226, 2019. DOI: 10.3844/ajeassp.2019.214.226. Disponível em: https://thescipub.com/abstract/10.3844/ajeassp.2019.214.226. Acesso em: 20 jun. 2019.

SHINGO, S. O Sistema Toyota de Produção do ponto de vista da Engenharia de Produção. 2. ed. Porto Alegre: Artes Médicas, 1996.

SOOSAY, C. et al. Strategies for sustaining manufacturing competitiveness: comparative case studies in Australia and Sweden. Journal of Manufacturing Technology Management, v. 27, p. 6-37, 2016. DOI: 10.1108/JMTM-04-2014-0043. Disponível em: https://www.emerald.com/insight/content/doi/10.1108/JMTM04-2014-0043/full/html. Acesso em: 05 jan. 2019.

SILVA, J. M. da . 5S: O ambiente da qualidade. Belo Horizonte: Fundação Christiano Ottoni, 1994. 